\title{
In vitro micro propagation of Rheum explants supplemented with various types of growth hormones
}

\author{
Shagoon Tabin ${ }^{1}$, R. C. Gupta ${ }^{2}$, Azra. N. Kamilii ${ }^{1 *}$ \\ ${ }^{1}$ Centre of Research for Development University of Kashmir Srinagar, \\ ${ }^{2}$ Department of Botany, Punjabi University, Patiala)
}

\begin{abstract}
Rheum species is a perennial stout herb, distributed in the temperate and sub tropical regions of Himalaya from Kashmir to Sikkim. The genus Rheum have been domesticated as medicinal plants for human consumption as its roots and stem are rich in anthraquinones such as Emodin and Rhein.Standardization of protocol for the micro propagation of Rheum using different types of explants and culture media supplemented with various types of growth hormones was carried out. Different parts (seeds, leaves, shoots and rhizomes) of Rheum were used as explants for tissue culture. These explants were first washed in laboline and tween 20 and after surface sterilization using different chemical sterilents, were cultured on different media and in combinations of phytohormones. All the explants showed good germination response with whole plant and roots exhibited about (98\%) response each while as seeds exhibited only 95\% germination.
\end{abstract}

Key words: Rheum explants, growth hormones, chemical sterilents

\section{Introduction}

Rheum species is a perennial stout herb, distributed in the temperate and sub tropical regions of Himalaya from Kashmir to Sikkim at elevation of 2800 and $3800 \mathrm{~m}$ (B. P. Nautiyal et.al., 2003).In Garhwal Himalaya it is generally found between 2800 and $3600 \mathrm{~m}$ in an alpine zone on rocky soil, between boulders and near streams. The Rheum belongs to the family Polygonaceae. Rheum can reach $2.5 \mathrm{~m}$ in height especially in fertile soil, being a strong vigorous plant, ready to live long even in tough condition, Rheum emodi can be found at elevations from 8,000 to 15,000 feet. This species has huge leaves which measure up to 3 feet in width. Rheum also prefers a full sunny location and thrives in a moist, fertile soil. Most Rheum can handle heavier clay soils better than many other herbs and makes a striking addition to the spring landscape. On a global basis, the IUCN has estimated that about $12.5 \%$ of the world's vascular plants, totalling about 34,000 species are under varying degrees of threat (Phartyal, et.al., 2002).IUCN (IUCN 1996) recognises the following categories: extinct in the wild, critically endangered, vulnerable, near threatened, least concern, data deficient and not evaluated together form the threatened category.

The genus Rheum have been domesticated as medicinal plants for human consumption as its roots and stem are rich in anthraquinones such as Emodin and Rhein.Recent research has shown that Rheum is an anti-cancer medicinal plant. Emodin (B. A. Zargar et.al., 2011) a component in Chinese Rheum root, has been found to inhibit the growth of cancer cells (V. Rajkumar et.al., 2011). In the wild population of Garhwal, emodin percent ranges between 0.81-1.88, rutin 0.24-0.93, chrysophenol 2.51-2.82 and chrysophenic acid between $0.35-1.08 \%$. It is used as strong laxative and is known for its astringent effect on the mucous membranes of the mouth and nasal cavity (Castleman M. 1991). Its astringent qualities help to improve bowel tone after it has purged the intestines, making it an excellent agent for improving the tone and health of the digestive tract (X. Peigen et.al., 1984). Its laxative effects make it a valuable aid in the treatment of chronic constipation, haemorrhoids and gastroenteritis. Skin eruptions caused by problems in elimination are also treated with Rheum roots. Its roots are also used in treating infant digestive problems constipation, or diarrhoea. Its roots have been found useful in controlling gastrointestinal haemorrhage by promoting the formation of blood platelets (Peirce 1991). This increase in the number of platelets shortens blood clotting time and is helpful in treating jaundice (Borgia.M et.al., 1981). It is also used as purgative and astringent tonic. Its stimulating effect combined with aspirin properties renders it especially useful in tonic dyspepsia. Rheum root has a purgative action for use in the treatment of constipation, but also has an astringent effect following this. It therefore has a truly cleansing action upon the gut, removing debris and then astringing with antiseptic properties (Duke 1997). In Ayurvedic Medicine, it is often given to children and the elderly in combination with ginger root for stomach troubles of all kinds, including diarrhoea from teething, pitta dysentery, jaundice and liver problems. It has astringent properties which tone the gut and helps remove waste while the anti-inflammatory and anti-bacterial qualities help in healing an inflamed intestine (Borgia.M et.al., 1981). It is used as an astringent tonic; it's stimulating effect combined with aperingent tonic; its stimulating effect combined with aperient properties render it especially useful in atonic dyspepsia. The essential oil content 
is $0.05 \%$ in the root, and its characteristic odor is due to the presence of eugenol (Chopra et.al., 1958). The total oxalic acid contents of the leaves and stems are reported to be 0.65 and 0.81 respectively.In the wild population of Garhwal, the percentage of emodin ranges between 0.81-1.88, chrysophenol 2.51-2.82, rutin 0.24-0.93 and chrysophenic acid between 0.35-1.08\% (Maithani 2001).

\section{Materials and Methods:}

Explants seeds, leaves, shoot tips, petioles, rhizomes \& roots were taken for culturing purpose directly from their natural habitat (In situ).

Removal of dirt and debris were necessary. Hence for this purpose explants were washed with a detergent (labolene) and rinsed several times with running tap water and distilled water before chemical sterilization procedure was carried out.

a) Seeds: seeds were soaked in water and were kept in refrigerator for 3 days. After 3 days they were taken out and were thoroughly washed with running tap water after cleaning them with detergent (labolene) and a few drops of Tween-20 (surfactant). This was followed by rinsing with pre-autoclaved double distilled water (DDW). After washing, seeds were subjected to chemical sterilization under laminar air flow cabinet.

b) Shoot tips, Nodal segments, Leaves, Roots, rhizomes and Petioles: All the explants were placed separately in a borosil beakers and same washing procedure as used in seeds was followed. The cleaned plant material was soaked in a sterilant solution under laminar air flow cabinet for different time durations to get complete removal of biological contaminants. After sterilization the explants were rinsed 3 times with autoclaved double distilled water (DDW). The aseptic explants were then subjected to trimming of cut ends on pre autoclaved and flame sterilized Petri plates with the help of sterilized surgical blades before inoculating these on sterilized nutrient medium.

\section{Results \&Discussion}

Germination of plant parts: The different explants i.e. whole plant, seeds and roots were planted for $\mathrm{g}$ ermination in green house of Kashmir University. All the explants showed good germination response with whole plant and roots exhibited about (98\%) response each while as seeds exhibited only $96 \%$ germination (Table 1).

Effect of Chemical Stimulants on explants: Standardization of protocol for the micro propagation of Rheum using different types of explants and culture media supplemented with various types of growth hormones was carried out. Different parts (seeds, leaves, shoots and rhizomes) of Rheum were used as explants for tissue culture. These explants were first washed in laboline and tween 20 and after surface sterilization using different chemical sterilents (Mercuric chloride \& Sodium hypochlorite). We observe a dose dependent survival response of seeds by using different concentrations of mercuric chloride. At the higher concentrations $(0.3 \%)$ about $80 \%$ seed explants survive (Table 2). Leaves show good response within a short period of time and about $90 \%$ survival takes place at a low concentrations of mercuric chloride $(0.1 \%)$ were cultured on different media i.e Linsmaier and skoog, Nitsch and Murashige and skoog medium, supplemented with different concentration and combinations of phytohormones ( BAP, Kn, IAA, NAA, IBA, 2,4-D and TDZ).

In vitro germination of explants: The complete germination with $90 \%$ germination response was noted on MS+ BAP $(10 \mu \mathrm{M})+$ sucrose $30 \mathrm{~g} / \mathrm{l}$ (fig. 1 a) followed by $85 \%$ on MS + 2, 4-D $(5 \mu \mathrm{M})+$ TDZ $(10 \mu \mathrm{M})+$ sucrose $30 \mathrm{~g} / \mathrm{l}$ (fig. $1 \mathrm{~b}$ ) and $75 \%$ on MS+ Kn $(10 \mu \mathrm{M})+\mathrm{NAA}(10 \mu \mathrm{M})+$ sucrose $30 \mathrm{~g} / \mathrm{l}$ (fig. $1 \mathrm{c})$. The optimum concentration for complete germination and whole plantlet formation was found to be MS+ BAP $(5 \mu \mathrm{M})+$ IBA $(5 \mu \mathrm{M})+$ sucrose $30 \mathrm{~g} / \mathrm{l}$ and $\mathrm{MS}+\mathrm{BAP}(10 \mu \mathrm{M})+$ sucrose $30 \mathrm{~g} / \mathrm{l}$. However, only rooting or in-complete germination was recorded on MS + Zeatin $(10 \mu \mathrm{M})+$ IAA $(2 \mu \mathrm{M})+$ sucrose $30 \mathrm{~g} / \mathrm{l}$. (fig. 1D (i)and D(ii)).

The callus formation was obtained on MS medium from leaf explants using different combinations and concentrations of phytohormones. The high callus formation was recorded with $90 \%$ response on MS + Zeatin $(7 \mu \mathrm{M})+2$, 4-D $(5 \mu \mathrm{M})+$ sucrose $30 \mathrm{~g} / \mathrm{l}$ (fig. 2 a), followed by moderate callus formation with $80 \%$ on $\mathrm{MS}+$ BAP $(5 \mu \mathrm{M})+2,4-\mathrm{D}(10 \mu \mathrm{M})+$ sucrose $30 \mathrm{~g} / \mathrm{l}$ (fig.2 b) and low callus formation with $60 \%$ on MS + Kn (10 $\mu \mathrm{M})+\operatorname{NAA}(5 \mu \mathrm{M})+$ sucrose $30 \mathrm{~g} / \mathrm{l}$. (fig.2 c). Hence the optimum concentration for callus formation with $94 \%$ response was on MS + BAP $(5 \mu \mathrm{M})+\mathrm{TDZ}(10 \mu \mathrm{M})+$ sucrose $30 \mathrm{~g} / \mathrm{l}$. The callus regenerated shoots will be screened for variance with enhanced production of active compounds/yield.

\section{Conclusion:}

Rheum emodi is an endangered plant and is under great threat. To avoid such threatening and to obtain more and more species of Rheum, we tried to standardize a protocol for the in vitro propagation of the plant using different explants and the combination of the various growth hormones. The combination of the different hormones and their concentration showed a varying effect on the germination of the explants. The explants gave a positive response under certain combinations and the complete germination and the whole plantlet were 
observed. The callus formation was obtained from leaf explants using different combinations and concentrations of phytohormones.

\section{References:}

[1]. B. A. Zargar, M. H. Masoodi, B. Ahmed, and S. A. Ganie, "Phytoconstituents and therapeutic uses of Rheum emodi wall.exMeissn," Food Chemistry, vol. 128, no. 3, pp. 585-589, 2011.

[2]. B. P. Nautiyal, V. Prakash, U. C. Maithani, R. S. Chauhan, H. Purohit, and M. C. Nautiyal, "Germinability, productivity and economic viability of Rheum emodiWall. exMeissn. Cultivated at lower altitude," Current Science, vol. 84, no. 2, pp. 143-148, 2003

[3]. Borgia M, Sepe N, Borgia R, Ori-Bellometti M. Pharmacological activity of an herbal extract: controlled clinical study. Curr Ther Res 1981; 29: 525-536

[4]. Borgia, M.; Sepe, N.; Borgia, R.; Ori-Bellometti, M. Pharmacological activity of an herbal extract: controlled clinical study. Current Therapeutic Research. 1981, (29), 525-536.

[5]. Castleman M. The Healing Herbs: The Ultimate guide to the curative powers of nature's medicine. Emmaus PA: Rodale Press, 1991: 305-307

[6]. Chopra, R N, I C Chopra, K L Handa and L D Kapuo Indigenous Drugs of India, Dhar \& Sons, Private Ltd., Calcutta(1958)

[7]. Duke JA. Green Pharmacy. Emmaus PA: Rodale Books, 1997: 507

[8]. IUCN ,WHO and WWF. Guidelines on the conservation of medicinal 0136-8.

plants.IUCN.Gland,Switzerland,1993,ISBN:2-8317-

[9]. Maithani, U C Ecophysiological and Biochemical Variability in Rheum Species From Garhwal Himalaya, Ph.D. Thesis (2001), HNB Garhwal University, Srinagar Garhwal.

[10]. Peirce A. The American Pharmaceutical Association practical to natural medicines. New York: William Morrow and Company Inc, 1999: 12

[11]. Phartyal, S.S., Thapliyal, R.C., Koedam, N.,Godefroid, S. Ex situ conservation of rare and valuable forest tree species through seed gene bank. Curr. Sci. 2002. 83: 1351-1357.

[12]. Rajkumar, G. Guha, and R. A. Kumar, "Antioxidant and anticancer potentials of Rheum emodi Rhizome extracts," Evidence-Based Complementary and Alternative Medicine, vol. 2011, Article ID 697986, 9 pages.

[13]. X. Peigen, H. Liyi, and W. Liwei, "Ethnopharmacologic study of Chinese rhubarb," Journal of Ethnopharmacology1984., vol. 10 , no. 3, pp. 275-293,

Table 1: Ex-situ conservation of genetic diversity of Rheum spp. in Green House, university of Kashmir.

\begin{tabular}{|l|l|l|}
\hline Explants used & Germination response & \% response \\
\hline Seeds & +++ & 96 \\
\hline Whole plant & +++ & 98 \\
\hline Roots & ++ & 98 \\
\hline$++=$ Slow Response,$+++=$ Fast Response & \\
\hline
\end{tabular}

Table 2: Effect of different chemical sterilants on percent contamination and survival of different explants of Rheum spp. in an invitro culture system.

\begin{tabular}{|l|l|l|l|l|}
\hline \multirow{4}{*}{ Explant } & $\begin{array}{l}\text { Chemical } \\
\text { sterilants } \\
\text { (Conc. \%) }\end{array}$ & $\begin{array}{l}\text { Duration } \\
(\mathbf{m i n})\end{array}$ & $\begin{array}{l}\text { Contamination } \\
(\boldsymbol{\%})\end{array}$ & $\begin{array}{l}\text { Explant survival } \\
(\boldsymbol{\%})\end{array}$ \\
\hline \multirow{4}{*}{ Seeds } & $\mathbf{H g C l}_{2}(\mathbf{0 . 0 3})$ & $\mathbf{1 5}$ & $\mathbf{1 0}$ & $\mathbf{8 0}$ \\
\cline { 2 - 6 } & $\mathrm{HgCl}_{2}(0.01)$ & 10 & 20 & 40 \\
\cline { 2 - 5 } & $\mathrm{HgCl}_{2}(0.02)$ & 5 & 60 & 20 \\
\hline \multirow{5}{*}{ Leaves } & $\mathrm{HgCl}_{2}(0.05)$ & 5 & 100 & - \\
\cline { 2 - 5 } & $\mathrm{HgCl}_{2}(0.05)$ & 10 & 70 & 20 \\
\cline { 2 - 5 } & $\mathrm{HgCl}_{2}(0.05)$ & 15 & 60 & 15 \\
\cline { 2 - 5 } & $\mathrm{HgCl}_{2}(0.05)$ & 20 & 40 & 5 \\
\cline { 2 - 5 } & $\mathrm{HgCl}_{2}(0.01)$ & 5 & $\mathbf{1 0}$ & $\mathbf{9 0}$ \\
\cline { 2 - 5 } & $\mathrm{HgCl}_{2}(\mathbf{0 . 0 1})$ & $\mathbf{3}$ & 5 & 0 \\
\cline { 2 - 5 } & $\mathrm{HgCl}_{2}(0.01)$ & 10 & & 50 \\
\hline
\end{tabular}


Fig 1: In Vitro germination of explants using different combination of various growth hormones.
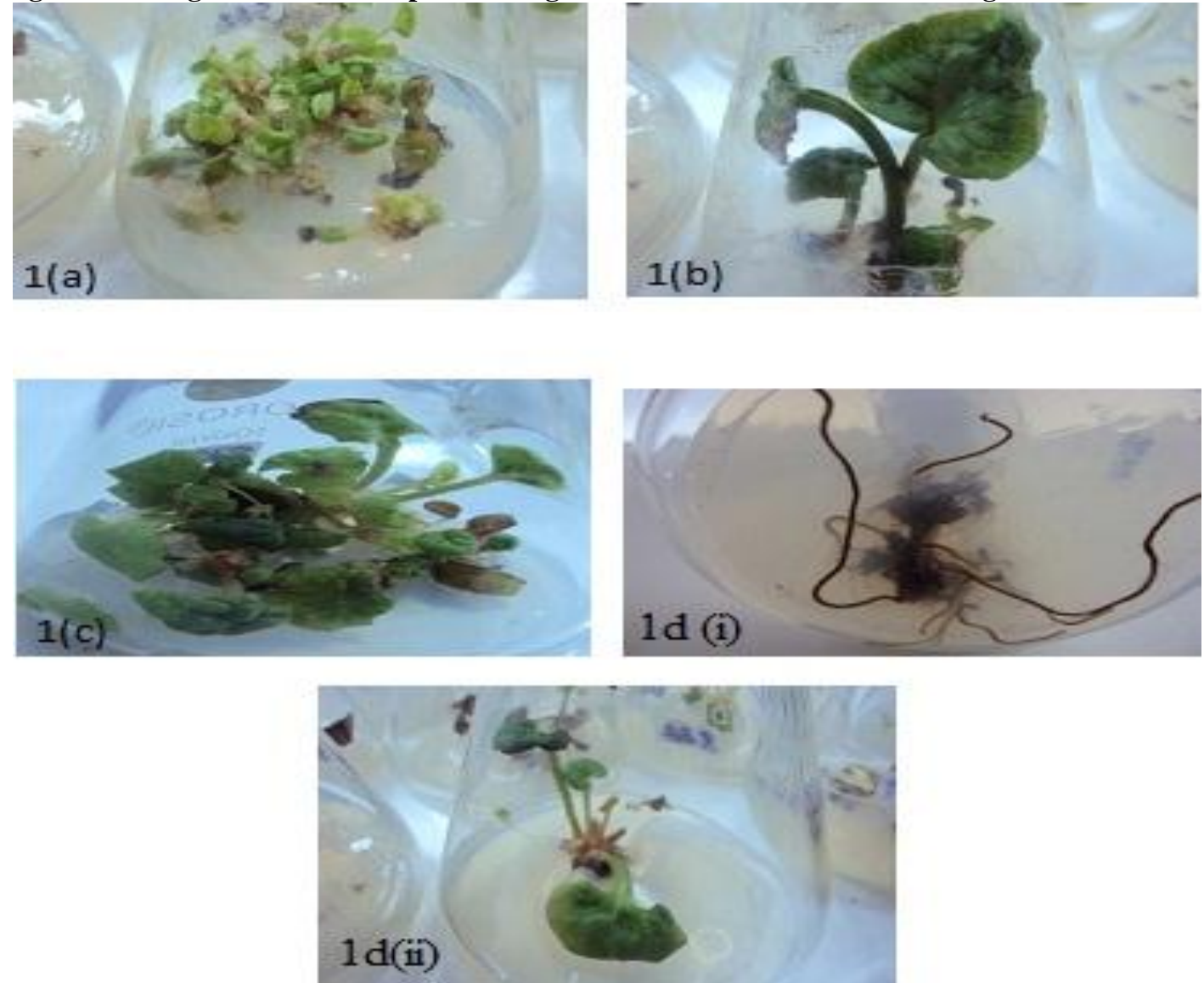

Fig 2: The callus formation from leaf explants using different combinations and concentrations of phytohormones.
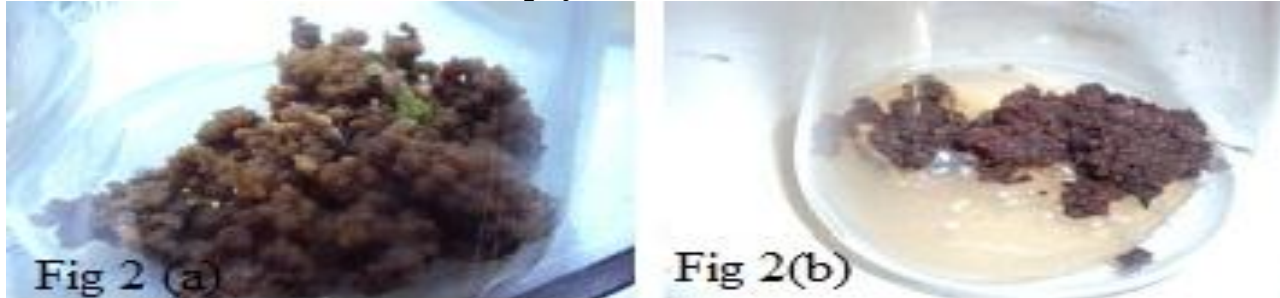

Fig 2(b)

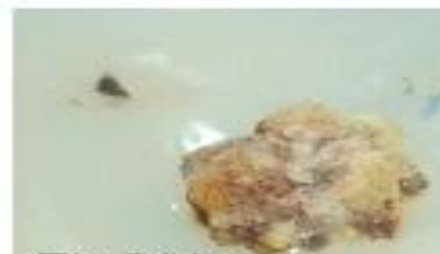

Fig 2(c) 